\title{
The Feasibility of Health Trainer Improved Patient Self-Management in Patients with Low Health Literacy and Poorly Controlled Diabetes: A Pilot Randomised Controlled Trial
}

\author{
Joanne Protheroe, 1 Trishna Rathod, ${ }^{1}$ Bernadette Bartlam, ${ }^{1}$ \\ Gillian Rowlands, ${ }^{2,3}$ Gerry Richardson, ${ }^{4}$ and David Reeves ${ }^{5}$ \\ ${ }^{1}$ Research Institute for Primary Care \& Health Sciences, Keele University, Keele, UK \\ ${ }^{2}$ Section for Health Promotion and Health Services, Institute for Public Health, Aarhus University, Aarhus, Denmark \\ ${ }^{3}$ Institute of Health and Society, University of Newcastle, Newcastle upon Tyne, UK \\ ${ }^{4}$ Centre for Health Economics, University of York, York, UK \\ ${ }^{5}$ Centre for Primary Care and Centre for Biostatistics, Manchester Academic Health Science Centre (MAHSC), \\ University of Manchester, Manchester, UK \\ Correspondence should be addressed to Joanne Protheroe; j.protheroe@keele.ac.uk
}

Received 26 August 2016; Accepted 28 September 2016

Academic Editor: Ulrike Rothe

Copyright (C) 2016 Joanne Protheroe et al. This is an open access article distributed under the Creative Commons Attribution License, which permits unrestricted use, distribution, and reproduction in any medium, provided the original work is properly cited.

Type 2 diabetes mellitus is most prevalent in deprived communities and patients with low health literacy have worse glycaemic control and higher rates of diabetic complications. However, recruitment from this patient population into intervention trials is highly challenging. We conducted a study to explore the feasibility of recruitment and to assess the effect of a lay health trainer intervention, in patients with low health literacy and poorly controlled diabetes from a socioeconomically disadvantaged population, compared with usual care. Methods. A pilot RCT comparing the LHT intervention with usual care. Patients with HbAlc $>7.5(58 \mathrm{mmol} / \mathrm{mol})$ were recruited. Baseline and 7-month outcome data were entered directly onto a laptop to reduce patient burden. Results. 76 patients were recruited; $60.5 \%$ had low health literacy and $75 \%$ were from the most deprived areas of England. Participants in the LHT arm had significantly improved mental health $(p=0.049)$ and illness perception $(p=0.040)$. The intervention was associated with lower resource use, better patient self-care management, and better QALY profile at 7-month follow-up. Conclusion. This study describes successful recruitment strategies for hard-to-reach populations. Further research is warranted for this cost-effective, relatively low-cost intervention for a population currently suffering a disproportionate burden of diabetes, to demonstrate its sustained impact on treatment effects, health, and health inequalities.

\section{Introduction}

Diabetes mellitus (DM) is a disorder of glucose metabolism suffered by over 4 million UK people, 90 per cent of whom have Type 2 diabetes $[1,2]$. Type 2 diabetes is more common in middle-aged or older people and greatest in deprived communities [3]. The risk of developing Type 2 diabetes can be reduced by lifestyle modification [4]. Deprivation is strongly associated with increased levels of obesity, physical inactivity, unhealthy diet, smoking, and poor blood pressure control, all potentially modifiable factors and all associated with an increased risk of developing diabetes or the risk of developing complications in people with diabetes [5]. The risk of developing complications such as heart disease, stroke, renal failure, and blindness is strongly linked to the tightness of glycaemic control [6, 7]. Patients' knowledge about diabetes and how to manage it, together with lifestyle choices, is central to the tightness of glycaemic control $[8,9]$.

Limited health literacy and numeracy skills are more common in areas of socioeconomic deprivation [10]. If this is 
linked with evidence that low health literacy is independently associated with worse glycaemic control and higher rates of diabetic complications, inadequate health literacy may be a significant factor in the disproportionate burden of diabetes and diabetes-related complications in more socioeconomically disadvantaged populations [11]. Studies have shown that people with low health literacy have lower levels of selfmanagement of chronic disease, including poorer diabetes self-management [12-14].

Individuals with inadequate health literacy are less likely to be recruited into research studies or randomised controlled trials of healthcare interventions $[15,16]$. This selection bias common to trials of interventions, may have implications for the likelihood of uptake of traditional diabetes educational interventions $[17,18]$. In summary, we have a population of people with Type 2 diabetes and low health literacy at increased risk of complications who may be ill-served by the currently available diabetes educational self-management programmes.

Lay health trainers (LHTs) are a UK government initiative using peer or lay educators, living in the local community, designed to reduce health inequalities by engaging with and focusing on deprived or hard-to-reach populations [19, 20]. They are intended to promote affordable, practical, socioculturally relevant lifestyle advice within communities.

This study aims to

(1) develop a LHT intervention to encourage patients to make healthy lifestyle choices in the management of Type 2 DM. This intervention is intended to improve patient self-management of their diabetes;

(2) to explore the feasibility of recruitment of patients, with low health literacy and poorly controlled diabetes from a socioeconomic disadvantaged population, to a trial of a LHT intervention;

(3) to collect data on a range of outcome measures and look for provisional indications of effectiveness and cost-effectiveness of the LHT intervention, in order to inform the design of a subsequent large-scale randomised controlled trial.

\section{Participants and Methods}

2.1. Sample. We conducted a pilot randomised controlled trial comparing the LHT intervention with usual care. Patients were recruited from six family doctor practices in Blackpool, from October 2012 to September 2013. Blackpool is the 6th most deprived local authority area in England and has a high prevalence of diabetes Type 2 (8.3\%) compared with a national average of $5.8 \%[21,22]$. Patients who were aged over 18 years with poorly controlled diabetes (HbAlc $>7.5$ or $58 \mathrm{mmol} / \mathrm{mol}$ in at least the last 2 measures) were eligible to be recruited. Those who were deemed ineligible by the practice staff (usually because of being too ill or too cognitively impaired to participate) were excluded.

Patients were identified and contacted by the practice nurse and informed about the study. Interested patients then had their contact details forwarded to the study research nurse. The research nurse contacted the patient to arrange an appointment to discuss the trial in depth at a face-to face meeting, either at home or at the practice as preferred by the patient. Consenting participants completed the baseline questionnaire and were randomised to one of the two trial arms (usual care or LHT).

Initially, potential participants were identified by the practice nurse at their routine review appointment from four family doctor practices. This yielded a poorer than expected recruitment and so the recruitment method was changed such that the practice nurse identified all potentially eligible patients and telephoned them to see if they would be interested in the study, rather than seeing the patient opportunistically at their routine check-up. Furthermore, an additional two family doctor practices were recruited to the trial.

2.2. Intervention. The intervention consisted of a structured interview with the LHT and development of an individualised patient self-management plan, plus up to three two-monthly support phone calls from the LHT (depending on agreements between the patient and the LHT) for a maximum of 6 months.

The structured interview supported the patient to identify areas where they could improve their health and used a locally developed menu (by collating existing locally available options) of support options available to that patient. Literacy skills teaching was not part of the intervention, but the LHT had information to enable them to, on request, signpost patients towards basic skills courses in their locality. The LHT did not provide medical or nursing advice. If the patient asked the LHT medical questions, patients were referred back to the practice nurse or family doctor. The LHTs had received training from the research team on evidence based diabetes care and appropriate lifestyle advice. In addition to providing information and advice aimed at changing key beliefs such as perceptions of risk from diabetes and the advantages and disadvantages of behaviour change, the LHTs advised them about essential health care tests and checks they should receive regularly as advised by Diabetes UK (blood pressure, cholesterol, feet and eye examinations, etc.). Using expertise from the research team, NHS Blackpool and Diabetes UK, the Wellness Service, employing the LHTs, developed a pamphlet designed for individuals with low health literacy to manage their diabetes [23].

Patients randomised to the control group received usual medical care. In the UK, usual care management of diabetes involves the family doctor practice keeping a register of all patients diagnosed with diabetes and usually inviting those patients into the practice for a review at least every 12 months. At this yearly review, usually led by the practice nurse, patients will be monitored and the following care processes should be undertaken: BMI measurement; BP measurement; haemoglobin Alc (HbAlc) measurement; cholesterol measurement; record of smoking status; foot examination; albumin: creatinine ratio; serum creatinine measurement.

2.3. Data Collection and Outcome Measures. To reduce the burden on the participant, the baseline demographics and 
outcomes were collected face-to-face by a research nurse who entered responses directly onto a security encrypted laptop. Outcomes were assessed at 7 months after randomisation via a telephone call from a different research nurse. Baseline demographics collected were age, gender, deprivation, health literacy, marital status, employment, ethnicity, and education. One aim of the pilot trial was to assess a broad spectrum of outcome measures (several of which overlap in health domains) for the purpose of selecting the most suitable subset for a larger trial in this population. Outcome measures included validated measures of diabetes self-care and quality of life, diabetes services and checks, EQ5D, mental well-being, illness perception, mental and physical health, resource use, and $\mathrm{HbAlc}$ values.

Deprivation. The index of multiple deprivation (IMD) 2010 is a measure of deprivation for small areas in England. It ranks areas from 1, the most deprived area, to 32,482 the least deprived area. The rank of deprivation is based on seven weighted domains: income; employment; education, skills, and training; health and disability; crime; barriers to housing and services; and living environment. Based on the participants' residential postcode, the rank of deprivation was obtained and then categorised into five groups with 1 being the most deprived area and 5 being the least deprived area in England [24].

Health Literacy. The Newest Vital Sign UK, validated for use with a UK population, was used to assess health literacy [25]. Participants were asked 6 questions based on a food label and a score of $\geq 4$ was deemed to indicate adequate health literacy and a score $<4$ was deemed as less than adequate.

Diabetes Self-Care. It was measured using the Summary of Diabetes Self-Care Activities Measure [26]. This is a validated brief self-report questionnaire of diabetes self-management that assesses general diet, specific diet, exercise, bloodglucose testing, foot care, and smoking.

Diabetes Quality of Life. It was assessed using The Diabetes Quality of Life Brief Clinical Inventory [27]. This is a short 15 -item scale that covers a broad range of issues ranging from patient satisfaction with their diabetes regimen to worries over diabetes symptoms and consequences.

Diabetes UK Scale Items. It is based on 9 questions (those applicable to primary care) out of 15 from Diabetes UK, relating to how many services and checks patients received to manage their diabetes; a total number of services and checks received was created [28].

Health-Related Quality of Life. It was assessed using the EQ5D which provides a measure of generic health-related quality of life [29]. This instrument enables the calculation of QALYs (quality adjusted life years), a composite measure of health obtained by weighing each period of follow-up time by the value corresponding to the health-related quality of life (HRQoL) during that period [30]. The values of the weights typically lie on a scale between zero (equivalent to death) and one (equivalent to full health), although negative values for states rated worse than dead are possible. This captures effects on both the quality and quantity of life used in assessment of health interventions in the UK health service [31]. The use of the QALY enables comparisons of the relative costeffectiveness of interventions to be made across a range of conditions.

Warwick-Edinburgh Mental Well-Being. It was assessed using the short version of the Warwick-Edinburgh Mental WellBeing scale which consists of 7 items to assess mental wellness [32].

Illness Perception. This was assessed using the Brief Illness Perception Score to assess the cognitive and emotional perceived illness [33].

Health Status Measure. It was assessed using the physical and mental health components of the SF12, which is a validated measure of overall health and daily activities [34].

Resource Use. It is the self-reported service use of family doctor and hospital care.

Haemoglobin Alc Values. Haemoglobin Alc values were extracted from the medical records. The closest available readings prior to date of randomisation and after 7 months were taken.

2.4. Sample Size. The primary aim of this pilot trial was to inform the design of a subsequent large-scale randomised controlled trial. Accordingly, the sample size was set to provide sufficient data to make reasonably accurate estimates of the underlying recruitment rate, statistical properties of the outcome measures, and some indication that the intervention has benefit for patients. On this basis, the target sample was set at 120 participants, allowing percentage recruitment to be estimated with an error of at most plus/minus $9 \%$ and the standard deviations of outcome measures to be between 0.89 and 1.14 times the actual value, with $95 \%$ confidence. With regard to patient benefit, although not powered to provide convincing evidence for a treatment effect (i.e., $p<0.05$ is unlikely to be found), low $p$-values on some of the major outcomes can be viewed as supporting the intervention's likely effectiveness. Allowing for $25 \%$ attrition, a follow-up sample of 90 patients would give $80 \%$ power to yield a $p$ value (two-tailed test) of 0.15 or less given a moderate to large effect size of the intervention (Cohen's $d$ of 0.5 or greater). The above calculations do not take account of clustering of outcome scores within practices but do give a general indication of sample adequacy.

2.5. Randomisation. Participants were randomly allocated on a 1:1 basis to either the LHT intervention or usual care. For each family doctor practice, a computer generated block randomisation list using block sizes of 2, 4, and 6 was produced by the statistician who was blind to treatment allocation. The sequence of treatment allocation was then sealed in opaque envelopes to be given to the participant from the research nurse once baseline data had been collected. 
Participants allocated to the intervention group were then given an appointment with the health trainer for commencement of the intervention. To avoid the risk of "contamination" between members of the same household if more than one person had diabetes, only 1 person was recruited per household. To maintain allocation concealment, the followup outcome data was collected by a different researcher at Keele University who was blind to treatment allocation.

2.6. Statistical Analysis. A consort flow diagram is presented (Figure 1). Descriptive statistics were used to assess whether the study had successfully recruited participants with low health literacy from a socioeconomic disadvantaged population. Descriptive statistics were used to assess balance of baseline characteristics between the trial arms and the distributional properties of each outcome measure. Analyses of the effectiveness of the LHT intervention at 7-month follow-up were conducted using an intention to treat approach within a linear regression framework. The primary analysis adjusted for baseline outcome scores only. To account for possible baseline differences on key prognostic factors, a sensitivity analysis was then performed adjusting also for age, gender, health literacy, family doctor practice, and length of time with diabetes. The assumptions of linear regression were verified. As this was an exploratory analysis looking solely for indications of effectiveness, imputation of missing values was not applied and all analyses were based on complete cases. All analyses were conducted in STATA v14.

2.7. Ethical Approval. Ethical approval was granted by the East Midlands, Derby National Research Ethics Service Committee on 16 August 2011, reference 11/EM/0294.

\section{Results}

3.1. Feasibility of Recruitment. Target recruitment was set at 120 patients; however, only 76 patients were recruited. Failure to reach target was due to the initial way potential participants were identified by the practice nurse with one family doctor practice failing to identify any potential participants.

Figure 1 is the consort flow diagram illustrating the flow of patients recruited to the trial. In summary, of the 290 eligible patients, $76(26.2 \%)$ were randomised, 37 to usual care and 39 to the LHT arms. One ineligible Type 1 diabetic patient was randomised and was removed from analysis. The overall follow-up rate at 7 months was $69.7 \%$ (53/76); the follow-up rates in the usual care and LHT arms were $70.3 \%(26 / 37)$ and $69.2 \%$ (27/39), respectively, indicating drop-out was not related to trial allocation.

3.2. Descriptive Statistics. Patient characteristics are summarised in Table 1. There were some differences between the two groups; the LHT arm was slightly older, had more females, had less retirees, and had diabetes for a longer period of time. The majority of the patients had poor health literacy and had come from a socioeconomic disadvantaged population. $46(60.5 \%)$ had less than adequate health literacy skill. Nationally, $20 \%$ of the UK population reside in each deprivation quintile. Compared to the rest of England, 75\% of the study sample resided in the most deprived areas of England, higher than the expected national level of $40 \%$.

3.3. Evaluation of Health Outcome Measures. Table 2 describes the distribution of each outcome at baseline and 7 months. With the exception of the EQ5D and Diabetes UK Score, the rest of the outcomes demonstrate good performance in having wide variation but only small floor or ceiling effects. The EQ5D and Diabetes UK Score show substantial floor and/or ceiling effects at baseline and/or 7 months: over $60 \%$ of patients have an EQ5D score in the top $20 \%$ of possible scores; and up to $40 \%$ have a Diabetes UK Score in the top $20 \%$ of possible scores. This suggests that the EQ5D and Diabetes UK Score may not be suitable outcomes to use in a further full trial as they have limited ability to detect change at the top end of the scale.

There were good indications that the LHT can improve patients' mental health; at 7 months, participants in the LHT (intervention) arm on average had a higher mental component score (mean difference between arms $=5.46,95 \%$ CI: $0.02,10.89, p=0.049$ ) and a less negative view on illness perception $(-5.74,95 \% \mathrm{CI}:-11.19,-0.29, p=0.040)$. Both of these results reached the conventional level of statistical significance of $p<0.05$. In terms of direction of change, participants in the LHT (intervention) arm had improved patient self-care management, received more health services and checks, and had better QALY profile but had worse haemoglobin Alc (all nonsignificant, but with $p$ values close to 0.2 ). However, there was less evidence for any impact on the physical health, well-being, and diabetes quality of life (Table 3). The pattern of results was essentially unchanged under sensitivity analysis adjusting for prognostic factors (Table 3), with the exception of haemoglobin Alc where the adjusted $p$ value suggested little effect on HbAlc over the length of this study.

3.4. Resource Use. The intervention was associated with lower resource use across all categories at 7-month follow-up. Results are presented in Table 4. The inpatient stay was lower in the LHT arm, though there were very few responses. It was assumed in the first case that missing values were in fact zero. However, conducting an analysis on those who completed the questionnaire and provided values for the first and/or second stay showed consistent results (inpatient stay mean for first stay was 13 days in usual care and 5.67 in LHT intervention and 8.5 and 0 for second visit). All of these results were not significant at conventional levels.

\section{Discussion}

This was a pilot randomised controlled trial of a lay health trainer (LHT) intervention to encourage patients to make healthy lifestyle choices in their self-management of Type 2 diabetes. The trial focused on the feasibility of recruitment of patients with low health literacy and poorly controlled diabetes from a socioeconomically disadvantaged population and evaluating its effect on diabetes self-management with 


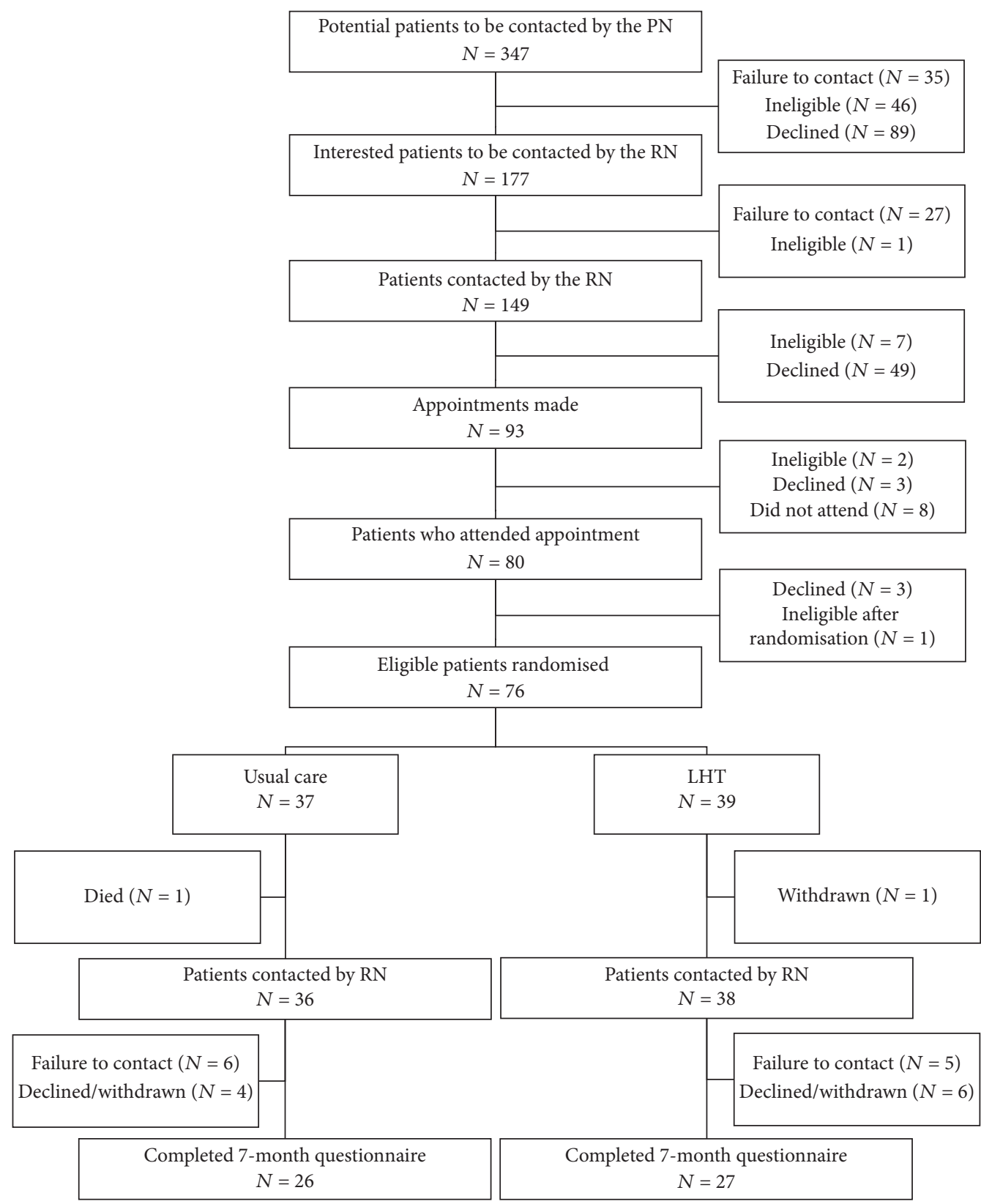

PN: practice nurse $\mathrm{RN}$ : research nurse

LHT: lay health trainer

FIGURE 1: Consort diagram.

a preliminary assessment of cost-effectiveness of the LHT intervention.

4.1. Recruiting from Disadvantaged Populations. As expected, recruiting participants with low health literacy from a socioeconomically disadvantaged population was challenging and required alterations to our recruitment strategy. At the outset, we had made the decision not to use postal written information as we were particularly interested in recruiting patients with low health literacy for whom written information might be less accessible. We had felt that personal contact from the practice nurse when the patient attended for their regular review would be more appropriate. However, this method proved to be slower in recruiting patients than was expected. When the study team explored this with our recruiting practices, it appeared that there were two reasons in particular for this; first, amongst all the clinical tasks that she was performing, often the practice nurse would fail to remember to mention the study and, second, the patients who were in this most at risk group were poor attenders of their review appointments. When we changed our recruitment strategy to support the practice staff to directly contact eligible 
TABLE 1: Baseline patient characteristics between usual care and health trainer.

\begin{tabular}{|c|c|c|}
\hline Patient characteristic & $\begin{array}{c}\text { Usual care } \\
N=37\end{array}$ & $\begin{array}{c}\text { Health trainer } \\
\quad N=39\end{array}$ \\
\hline Age (mean (SD)) & $61.5(10.1)$ & $64.7(11.2)$ \\
\hline \multicolumn{3}{|l|}{ Sex } \\
\hline Male & $22(59.5)$ & $16(41.0)$ \\
\hline Female & $15(40.5)$ & $23(59.0)$ \\
\hline \multicolumn{3}{|l|}{ Deprivation } \\
\hline Most deprived & $11(29.7)$ & $13(33.3)$ \\
\hline 2nd most deprived & $16(43.2)$ & $17(43.6)$ \\
\hline Mid-deprived & $8(21.6)$ & $5(12.8)$ \\
\hline 2nd least deprived & $2(5.4)$ & $4(10.3)$ \\
\hline Least deprived & $0(0)$ & $0(0)$ \\
\hline \multicolumn{3}{|l|}{ Employment status } \\
\hline Paid work & $13(35.1)$ & $15(38.5)$ \\
\hline Retired & $17(46.0)$ & $15(38.5)$ \\
\hline Long-term sick/disabled & $6(16.2)$ & $6(15.4)$ \\
\hline Seeking employment/volunteer work/looking after home or family & $1(2.7)$ & $3(7.7)$ \\
\hline \multicolumn{3}{|l|}{ Marital status } \\
\hline Never married & $7(18.9)$ & $4(10.3)$ \\
\hline Married/civil partnership & $21(56.8)$ & $21(53.9)$ \\
\hline Separated/divorced/widowed & $9(24.3)$ & $14(35.9)$ \\
\hline \multicolumn{3}{|l|}{ Lives alone } \\
\hline Yes & $9(24.3)$ & $10(27.0)$ \\
\hline No & $28(75.7)$ & $27(74.0)$ \\
\hline \multicolumn{3}{|l|}{ How long patient had diabetes (years) } \\
\hline$<5$ years & $11(29.7)$ & $4(10.3)$ \\
\hline$\geq 5$ years & $26(70.3)$ & $35(89.7)$ \\
\hline \multicolumn{3}{|l|}{ Number of comorbidities } \\
\hline $0-1$ & $8(21.6)$ & $12(30.8)$ \\
\hline $2-3$ & $18(48.7)$ & $21(53.9)$ \\
\hline $4-5$ & $11(29.7)$ & $6(15.4)$ \\
\hline \multicolumn{3}{|l|}{ Highest qualification obtained } \\
\hline School level including O-level/CSEs/GCSEs/School certificate or none & $9(26.5)$ & $21(53.9)$ \\
\hline A-level or vocational including NVQ/HNC/HND/professional qualification/other & $22(64.7)$ & $16(41.0)$ \\
\hline University (first or higher education) & $3(8.8)$ & $2(5.1)$ \\
\hline \multicolumn{3}{|l|}{ Health literacy } \\
\hline Adequate & $17(46.0)$ & $13(33.3)$ \\
\hline Inadequate & $20(54.0)$ & $26(66.7)$ \\
\hline \multicolumn{3}{|l|}{ Socioeconomic status } \\
\hline Higher managerial administration and professional occupations & $9(24.3)$ & $10(25.6)$ \\
\hline Intermediate occupations & $10(27.0)$ & $12(30.8)$ \\
\hline Routine and manual occupations & $18(48.7)$ & $17(43.6)$ \\
\hline \multicolumn{3}{|l|}{ Feeling down, depressed, or hopeless (QOF depression screen 1) } \\
\hline Yes & $16(43.2)$ & $15(38.5)$ \\
\hline No & $21(56.8)$ & $24(61.5)$ \\
\hline \multicolumn{3}{|l|}{ Little interest or pleasure in doing things (QOF depression screen 2) } \\
\hline Yes & $17(46.0)$ & $16(41.0)$ \\
\hline No & $20(54.1)$ & $23(59.0)$ \\
\hline
\end{tabular}


TABLE 2: Adequacy of outcome measures.

\begin{tabular}{|c|c|c|c|c|c|c|c|c|}
\hline $\begin{array}{l}\text { Outcome } \\
\text { measure }\end{array}$ & $\begin{array}{l}\text { Number of } \\
\text { patients } \\
\text { answering all } \\
\text { scale items } \\
N(\%)\end{array}$ & $\begin{array}{c}\text { Range of } \\
\text { possible } \\
\text { scores }\end{array}$ & $\begin{array}{c}\text { Mean score } \\
(\mathrm{SD})\end{array}$ & $\begin{array}{c}\text { Range of } \\
\text { observed } \\
\text { scores }\end{array}$ & $\begin{array}{l}\text { Number of } \\
\text { patients with } \\
\text { minimum } \\
\text { possible score } \\
N(\%)\end{array}$ & $\begin{array}{l}\text { Number of } \\
\text { patients with } \\
\text { maximum } \\
\text { possible score } \\
N(\%)\end{array}$ & $\begin{array}{c}\text { Number of } \\
\text { patients } \\
\text { scoring in the } \\
\text { bottom } 20 \% \text { of } \\
\text { possible scores } \\
N(\%)\end{array}$ & $\begin{array}{l}\text { Number of } \\
\text { patients } \\
\text { scoring in the } \\
\text { top } 20 \% \text { of } \\
\text { possible scores } \\
N(\%)\end{array}$ \\
\hline $\begin{array}{l}\text { Baseline: } \\
\text { SDSCAM }\end{array}$ & $76(100)$ & 0,7 & $3.83(1.48)$ & $0.22,6.89$ & $0(0)$ & $0(0)$ & $4(5.3)$ & $7(9.2)$ \\
\hline $\begin{array}{l}7 \text { months: } \\
\text { SDSCAM }\end{array}$ & $52(98.1)$ & 0,7 & $4.01(1.24)$ & $0.89,6.78$ & $0(0)$ & $0(0)$ & $1(1.9)$ & $5(9.6)$ \\
\hline $\begin{array}{l}\text { Baseline: } \\
\text { SWEMWBS }\end{array}$ & $76(100)$ & 7,35 & $22.93(5.30)$ & $13.30,35.00$ & $0(0)$ & $3(4.0)$ & $0(0)$ & $8(10.5)$ \\
\hline $\begin{array}{l}7 \text { months: } \\
\text { SWEMWBS }\end{array}$ & $52(98.1)$ & 7,35 & $22.81(4.22)$ & $7.00,30.70$ & $1(1.9)$ & $0(0)$ & $1(1.9)$ & $2(3.8)$ \\
\hline Baseline: PCS & $76(100)$ & 0,100 & $36.90(10.64)$ & $9.94,56.15$ & $0(0)$ & $0(0)$ & $6(7.9)$ & $0(0)$ \\
\hline $\begin{array}{l}7 \text { months: } \\
\text { PCS }\end{array}$ & $53(100)$ & 0,100 & $35.36(13.04)$ & $7.89,56.15$ & $0(0)$ & $0(0)$ & $5(9.4)$ & $0(0)$ \\
\hline $\begin{array}{l}\text { Baseline: } \\
\text { MCS }\end{array}$ & $76(100)$ & 0,100 & $45.44(12.76)$ & $15.36,65.63$ & $0(0)$ & $0(0)$ & $3(9.2)$ & $0(0)$ \\
\hline $\begin{array}{l}7 \text { months: } \\
\text { MCS }\end{array}$ & $53(100)$ & 0,100 & $49.16(12.12)$ & $17.36,74.12$ & $0(0)$ & $0(0)$ & $1(1.9)$ & $0(0)$ \\
\hline $\begin{array}{l}\text { Baseline: } \\
\text { DQL }\end{array}$ & $76(100)$ & 0,100 & $34.12(24.05)$ & 0,100 & $2(2.6)$ & $2(2.6)$ & $19(25)$ & $5(6.6)$ \\
\hline $\begin{array}{l}7 \text { months: } \\
\text { DQL }\end{array}$ & $48(90.6)$ & 0,100 & $39.06(25.98)$ & 0,100 & $2(4.2)$ & $1(2.1)$ & $9(18.8)$ & $4(14.6)$ \\
\hline $\begin{array}{l}\text { Baseline: } \\
\text { BIPS }\end{array}$ & $76(100)$ & 0,80 & $38.46(12.80)$ & 11,63 & $0(0)$ & $0(0)$ & $3(3.9)$ & $0(0)$ \\
\hline $\begin{array}{l}7 \text { months: } \\
\text { BIPS }\end{array}$ & $52(98.1)$ & 0,80 & $38.33(12.01)$ & 12,68 & $0(0)$ & $0(0)$ & $2(3.8)$ & $2(3.8)$ \\
\hline $\begin{array}{l}\text { Baseline: } \\
\text { DUKS }\end{array}$ & $76(100)$ & 0,9 & $6.97(1.15)$ & 3,9 & $0(0)$ & $1(1.3)$ & $0(0)$ & $27(35.5)$ \\
\hline $\begin{array}{l}7 \text { months: } \\
\text { DUKS }\end{array}$ & $52(98.1)$ & 0,9 & $7.15(1.24)$ & 4,9 & $0(0)$ & $8(15.5)$ & $0(0)$ & $21(40.4)$ \\
\hline $\begin{array}{l}\text { Baseline: } \\
\text { HblAc }\end{array}$ & $76(100)$ & - & 78.04 (15.17) & 56,121 & - & - & - & - \\
\hline $\begin{array}{l}7 \text { months: } \\
\text { HblAc }\end{array}$ & $61(80.3)$ & - & $72.64(16.71)$ & 41,117 & - & - & - & - \\
\hline $\begin{array}{l}\text { Baseline: } \\
\text { EQ5D }\end{array}$ & $76(100)$ & $-0.59,1$ & $0.59(0.35)$ & $-0.24,1.00$ & $0(0)$ & $12(15.8)$ & $0(0)$ & 47 (61.8) \\
\hline $\begin{array}{l}7 \text { months: } \\
\text { EQ5D }\end{array}$ & $52(98.1)$ & $-0.59,1$ & $0.64(0.28)$ & $-0.02,1.00$ & $0(0)$ & $7(13.5)$ & $0(0)$ & $31(59.6)$ \\
\hline
\end{tabular}

Summary Diabetes Self-Care Measure (SDSCAM); Short Warwick-Edinburgh Mental Well-Being Score (SWEMWBS); SF-12 Physical and Mental Component Scores (PCS \& MCS); Diabetes Quality of Life (DQL); Brief Illness Perception Score (BIPS); Diabetes UK Score (DUKS); EuroQuol Health questionnaire (EQ$5 \mathrm{D})$.

patients by telephone and discuss their potential participation in the trial, we were more successful in recruiting this disadvantaged population. This finding adds weight to the argument that it is not the particular population that is problematic but the failure to adopt recruitment strategies sensitive to contributing factors that may have an impact on participation [35]. With this method, as can be seen from the consort diagram in Figure 1, only 89 out 347 (25\%) declined to be contacted further. However, the numbers of patients declining to participate once they spoke to the study team and failure to make contact with participants for follow-up were quite significant in this population.
Despite these substantial challenges, this method of recruitment was successful in recruiting a study population, $75 \%$ of whom were from the most deprived areas of England and over $60 \%$ had low health literacy (as measured by the NVS) [25]. This compares well to other studies of LHTs which were less successful in this aspect and tended to recruit more affluent populations [36].

4.2. Effect of Intervention. Given that this was a feasibility pilot trial and powered accordingly, nonetheless, these provisional results show that the LHT had a significant 


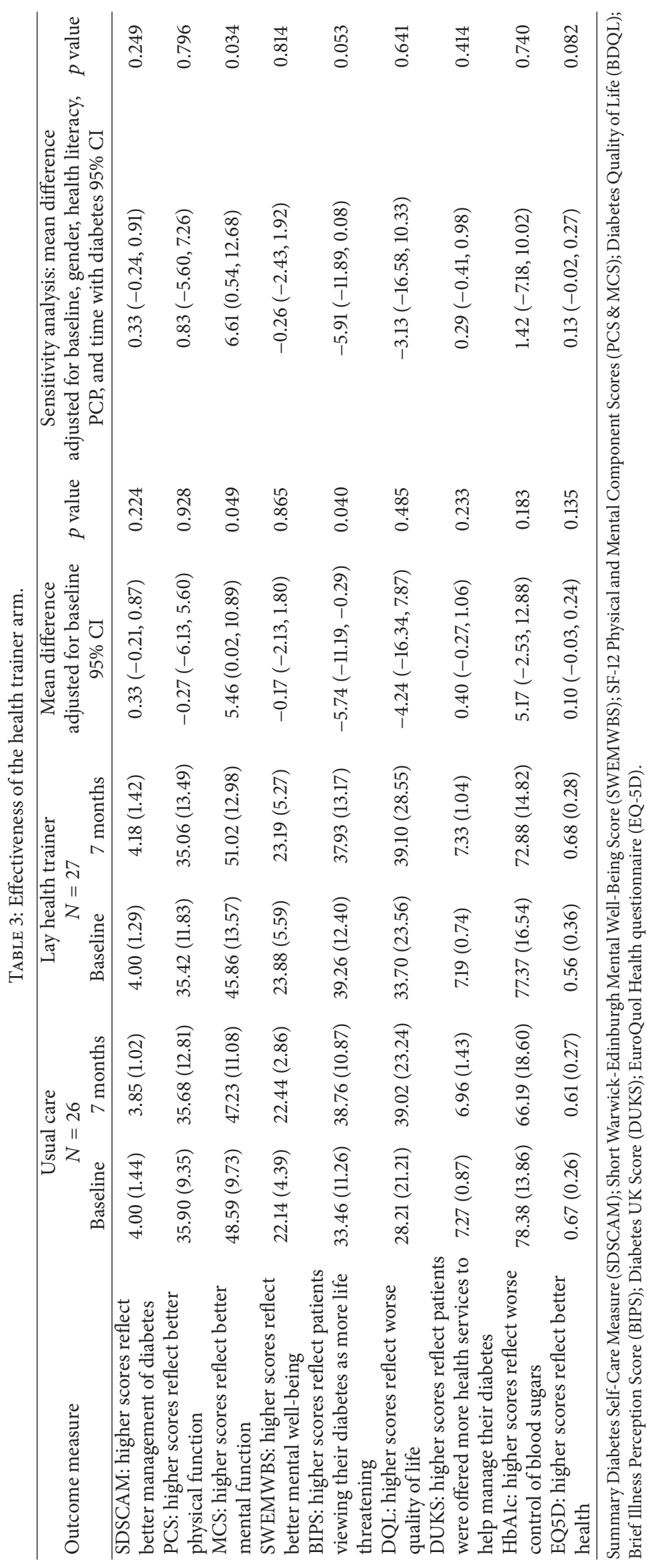


TABLE 4: Resource use by group (number of contacts) at 7 months based on complete cases.

\begin{tabular}{|c|c|c|c|c|}
\hline & $\begin{array}{l}\text { Usual care } \\
N=26 \\
\text { Mean }(\mathrm{SD})\end{array}$ & $\begin{array}{l}\text { Lay health } \\
\text { trainer } \\
N=27 \\
\text { Mean (SD) }\end{array}$ & $\begin{array}{l}\text { Unadjusted } \\
\text { difference } \\
(95 \% \text { CI })\end{array}$ & $p$ value \\
\hline $\begin{array}{l}\text { Inpatient } \\
\text { (number of } \\
\text { nights) }\end{array}$ & $3.12(8.34)$ & $1.26(3.40)$ & $\begin{array}{c}-1.86(-5.35 \\
1.63)\end{array}$ & 0.291 \\
\hline $\begin{array}{l}\text { A\&E } \\
\text { attendance }\end{array}$ & $0.54(1.03)$ & $0.46(0.86)$ & $\begin{array}{c}-0.08(-0.60 \\
0.45)\end{array}$ & 0.771 \\
\hline $\begin{array}{l}\text { Outpatient } \\
\text { visits }\end{array}$ & $1.19(1.86)$ & $0.65(0.89)$ & $\begin{array}{c}-0.54(-1.35 \\
0.27)\end{array}$ & 0.188 \\
\hline GP at surgery & $2.58(2.16)$ & $1.65(1.60)$ & $\begin{array}{c}-0.92(-1.98 \\
0.13)\end{array}$ & 0.086 \\
\hline GP at home & $0.04(0.20)$ & $0(0)$ & $\begin{array}{c}-0.04(-0.12 \\
0.04)\end{array}$ & 0.322 \\
\hline $\begin{array}{l}\text { Practice } \\
\text { nurse }\end{array}$ & $2.12(2.10)$ & $1.73(1.15)$ & $\begin{array}{c}-0.38(-1.33 \\
0.56)\end{array}$ & 0.417 \\
\hline
\end{tabular}

${ }^{*}$ Based on the assumption that missing values were zeros.

impact on the mental health of participants in the intervention arm, both in terms of the mental health component of the SF12 and in patients having a less negative self-perception of their condition. There may be a variety of reasons underlying this; research evidence suggests that patients with low health literacy can be especially anxious about medication use and dissatisfied with information that they receive about diabetes [37]. Additionally, other research has suggested that enhanced social support (signposted to or directly provided by the LHT) may improve diabetes self-care [38]. Furthermore, although not achieving conventional statistical significance in this small sample size, the results suggest that participants in the LHT arm had improved patient self-care management and received more health services and checks, all of which are likely to positively impact participants' mental health and their perceptions of their condition. This is supported by a relatively large increase in quality adjusted life years (QALYs) over a short seven-month period.

The LHT intervention in this pilot trial did not lead to improvements in physical health or blood-glucose control as measured by the HbAlc, but the sample was not powered to investigate changes in $\mathrm{HbAlc}$ and it is likely that an intervention of this nature, designed to improve patient self-management by encouraging patient behaviour change, would need longer than the short follow-up of this study to demonstrate an impact on physical health.

4.3. Preliminary Cost-Effectiveness. The LHT intervention was associated with lower resource use across all categories (primary and secondary care) at follow-up. While none of these differences were clinically significant, these results add weight to the possibility that the relatively minimal costs of the intervention may be offset by reductions in downstream costs. In addition, the intervention was associated with a better QALY profile than the control group. While this difference was small (and nonsignificant), it supports the general results of this study that the intervention may provide good value for money and may even save money while improving outcomes.

Research evidence on the cost-effectiveness of lay health advisors, which would include LHTs, is mixed, but an evidence synthesis by Carr et al. suggests that they can be cost-effective in chronic care and smoking cessation, both important for diabetes self-management [39].

4.4. Limitations of This Study. Despite relatively successful efforts to recruit a disadvantaged population of patients with poorly controlled diabetes and low health literacy, from socioeconomically deprived areas, there remains the possibility that the trial participants are still underrepresentative of those who are most disadvantaged and most at risk. Such individuals may be less motivated to respond to the LHT intervention and less willing to respond to supported selfmanagement to improve their poorly controlled diabetes.

Being a pilot, the trial was not fully powered for the detection of intervention effects and the inclusion of a wide range of outcomes implies a high chance of one or more falsely significance results; hence, the findings on effectiveness must be treated as purely provisional until validated by further, larger, studies. A further limitation is the short length of follow-up. This is particularly relevant to interventions which are intended to lead to change in outcome measures through behaviour change, which will likely need a reasonable length of time to make an impact. This would need to be evaluated in a full-size RCT with longer follow-up.

4.5. What This Study Adds. This study adds to the body of evidence regarding recruiting disadvantaged participants, specifically those with low health literacy, living in socioeconomically disadvantaged areas. We would support recruitment strategies that keep written information to a minimum and recruit using personal contact by someone known to the potential participant. As previously mentioned, a future fullsized RCT would need to aim for longer follow-up of 12-18 months to be confident about sustained improvements in mental health and the possibility of improvements in patient self-management leading to significant improvements in physical health. As discussed in the results, follow-up in this study at 7 months was just under $70 \%$, so collecting longer term follow-up data will be challenging and may require the use of other more innovative practices such as the use of text messaging and social media to collect data, keeping in mind health literacy limitations.

\section{Conclusion}

Despite the initial low response to recruitment using practice nurses, changes in our recruitment strategy led to this pilot trial recruiting the population that it set out to achieve. To our knowledge, this is the first pilot trial to provide evidence for recruiting patients with low health literacy from disadvantaged backgrounds and to demonstrate the feasibility of a LHT RCT in a primary care setting for this population that is usually excluded from RCTs by nature of their poor 
response to invites to research. Adding to this the likely cost-effectiveness of this relatively low-cost intervention to a population currently suffering a disproportionate burden of diabetes and diabetes-related complications, we would support a large, robust RCT to demonstrate the treatment effect and its sustained impact on health and health inequalities.

\section{Disclosure}

The views expressed are those of the authors and not necessarily those of the NHS, the NIHR, or the Department of Health.

\section{Competing Interests}

The authors declare that they have no competing interests.

\section{Acknowledgments}

The authors acknowledge Blackpool Primary Care Trust, Public Health, and Blackpool Council, Public Health. The authors also acknowledge the patients who kindly participated and the managers and staff who participated and supported the study. This project presents independent research funded by the National Institute for Health Research (NIHR) under its Research for Patient Benefit Programme (Grant Reference no. PB-PG-0110-20033).

\section{References}

[1] Department of Health Social Services and Public Safety, Quality and Outcomes Framework, Health and Social Care Information Centre, 2014-2015.

[2] Scottish Diabetes Survey Monitoring Group, National Diabetes Audit Report 1: Care Processes and Treatment Targets, 2012-2013.

[3] Health Survey for England. (2011, 01.04.2016), Chapter 4, https://www.gov.uk/government/publications/health-surveyfor-england-2011.

[4] J. Tuomilehto, J. Lindström, J. G. Eriksson et al., "Prevention of type 2 diabetes mellitus by changes in lifestyle among subjects with impaired glucose tolerance," The New England Journal of Medicine, vol. 344, no. 18, pp. 1343-1350, 2001.

[5] All Party Parliamentary Group for Diabetes and Diabetes UK, Diabetes and the Disadvantaged: Reducing Health Inequalities in the UK: World Diabetes Day 14 November 2006, 2006.

[6] C. E. Nasr, B. J. Hoogwerf, C. Faiman, and S. S. K. Reddy, "Effects of glucose and blood pressure control on complications of type 2 diabetes mellitus," Cleveland Clinic Journal of Medicine, vol. 66, no. 4, pp. 247-253, 1999.

[7] I. M. Stratton, A. I. Adler, H. A. W. Neil et al., "Association of glycaemia with macrovascular and microvascular complications of type 2 diabetes (UKPDS 35): prospective observational study," British Medical Journal, vol. 321, no. 7258, pp. 405-412, 2000.

[8] Diabetes UK, Smoking and Diabetes, 2016, https://www .diabetes.org.uk/Guide-to-diabetes/Teens/Me-and-my-diabetes/ Living-my-life/Smoking/.

[9] Diabetes UK, Diabetes: Treatment and Your Health: Eating with Diabetes, 2016, https://www.diabetes.org.uk/Guide-todiabetes/Enjoy-food/.

[10] G. Rowlands, J. Protheroe, J. Winkley, M. Richardson, P. T. Seed, and R. Rudd, "A mismatch between population health literacy and the complexity of health information: an observational study," British Journal of General Practice, vol. 65, no. 635, pp. e379-e386, 2015.

[11] D. Schillinger, K. Grumbach, J. Piette et al., "Association of health literacy with diabetes outcomes," Journal of the American Medical Association, vol. 288, no. 4, pp. 475-482, 2002.

[12] S. Kim, F. Love, D. A. Quistberg, and J. A. Shea, "Association of health literacy with self-management behavior in patients with diabetes," Diabetes Care, vol. 27, no. 12, pp. 2980-2982, 2004.

[13] M. V. Williams, D. W. Baker, E. G. Honig, T. M. Lee, and A. Nowlan, "Inadequate literacy is a barrier to asthma knowledge and self-care," Chest, vol. 114, no. 4, pp. 1008-1015, 1998.

[14] S. C. Kalichman, B. Ramachandran, and S. Catz, "Adherence to combination antiretroviral therapies in HIV patients of low health literacy," Journal of General Internal Medicine, vol. 14, no. 5, pp. 267-273, 1999.

[15] J. Livaudais-Toman, N. J. Burke, A. Napoles, and C. P. Kaplan, "Health literate organizations: are clinical trial sites equipped to recruit minority and limited health literacy patients?" Journal of Health Disparities Research and Practice, vol. 7, pp. 1-13, 2014.

[16] D. C. Blanch, R. E. Rudd, E. Wright, V. Gall, and J. N. Katz, "Predictors of refusal during a multi-step recruitment process for a randomized controlled trial of arthritis education," Patient Education and Counseling, vol. 73, no. 2, pp. 280-285, 2008.

[17] B. S. Gerber, I. G. Brodsky, K. A. Lawless et al., "Implementation and evaluation of a low-literacy diabetes education computer multimedia application," Diabetes Care, vol. 28, no. 7, pp. 15741580, 2005.

[18] B. A. Coonrod, J. Betschart, and M. I. Harris, "Frequency and determinants of diabetes patient education among adults in the U.S. population," Diabetes Care, vol. 17, no. 8, pp. 852-858, 1994.

[19] S. Lewin, S. Munabi-Babigumira, C. Glenton et al., "Lay health workers in primary and community health care for maternal and child health and the management of infectious diseases," Cochrane Database of Systematic Reviews, no. 3, Article ID CD004015, 2010.

[20] S. A. Lewin, J. Dick, P. Pond et al., "Lay health workers in primary and community health care," Cochrane Database of Systematic Reviews, no. 1, Article ID CD004015, 2005.

[21] Public Health Intelligence, Diabetes in Lancashire, 2012.

[22] Diabetes UK, https://www.diabetes.org.uk/prevalence-2012.

[23] Blackpool Wellness Service, "Living well with diabetes," 2013.

[24] "The English Indices of Deprivation 2010," Department for Communities and Local Government (England), 2011.

[25] G. Rowlands, N. Khazaezadeh, E. Oteng-Ntim, P. Seed, S. Barr, and B. D. Weiss, "Development and validation of a measure of health literacy in the UK: the newest vital sign," BMC Public Health, vol. 13, article 116, 2013.

[26] D. J. Toobert, S. E. Hampson, and R. E. Glasgow, “The summary of diabetes self-care activities measure: results from 7 studies and a revised scale," Diabetes Care, vol. 23, no. 7, pp. 943-950, 2000.

[27] T. E. Burroughs, R. Desikan, B. M. Waterman, D. Gilin, and J. McGill, "Development and validation of the diabetes quality of life brief clinical inventory," Diabetes Spectrum, vol. 17, no. 1, pp. 41-49, 2004.

[28] Diabetes UK, 15 Healthcare Essentials, https://www.diabetes .org.uk/Guide-to-diabetes/Monitoring/15-healthcare-essentials/.

[29] EuroQuol Group, EQ-5D Health Questionnaire. 
[30] P. Dolan, C. Gudex, P. Kind, and A. Williams, "A social tariff for EuroQol: results from a UK general population survey," CHE Discussion Paper 138, Centre for Health Economics, York, UK, 1995.

[31] National Institute for Health and Care Excellence, Glossary, https://www.nice.org.uk/glossary?letter=q.

[32] S. Stewart-Brown, A. Tennant, R. Tennant, S. Platt, J. Parkinson, and S. Weich, "Internal construct validity of the WarwickEdinburgh Mental Well-Being Scale (WEMWBS): a Rasch analysis using data from the Scottish Health Education Population Survey," Health and Quality of Life Outcomes, vol. 7, article 15, 2009.

[33] E. Broadbent, K. J. Petrie, J. Main, and J. Weinman, "The brief illness perception questionnaire," Journal of Psychosomatic Research, vol. 60, no. 6, pp. 631-637, 2006.

[34] “The SF-12 ${ }^{\circledR}:$ An Even Shorter Health Survey," 2015, http://www .sf-36.org/tools/sf12.shtml.

[35] A. Shaghaghi, R. S. Bhopal, and A. Sheikh, "Approaches to recruiting 'hard-to-reach' populations into re-search: a review of the literature," Health Promot Perspect, vol. 1, pp. 86-94, 2011.

[36] M. Goodall, G. R. Barton, P. Bower et al., "Food for thought: pilot randomized controlled trial of lay health trainers supporting dietary change to reduce cardiovascular disease in deprived communities," Journal of Public Health, vol. 36, no. 4, pp. 635643, 2014

[37] J. E. Aikens and J. D. Piette, "Diabetic patients' medication underuse, illness outcomes, and beliefs about antihyperglycemic and antihypertensive treatments," Diabetes Care, vol. 32, no. 1, pp. 19-24, 2009.

[38] C. Y. Osborn, S. S. Bains, and L. E. Egede, "Health literacy, diabetes self-care, and glycemic control in adults with type 2 diabetes," Diabetes Technology and Therapeutics, vol. 12, no. 11, pp. 913-919, 2010.

[39] S. M. Carr, M. Lhussier, N. Forster et al., "An evidence synthesis of qualitative and quantitative research on component intervention techniques, effectiveness, cost-effectiveness, equity and acceptability of different versions of health-related lifestyle advisor role in improving health," Health Technology Assessment, vol. 15, no. 9, pp. 1-284, 2011. 


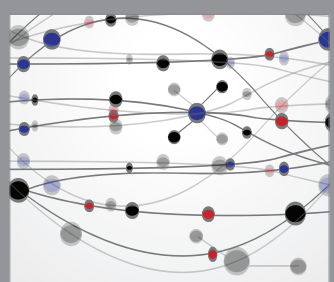

The Scientific World Journal
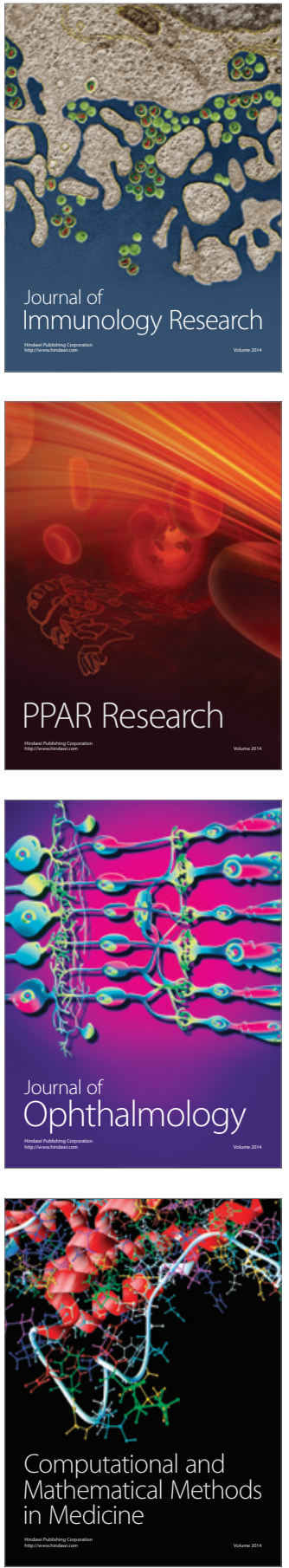

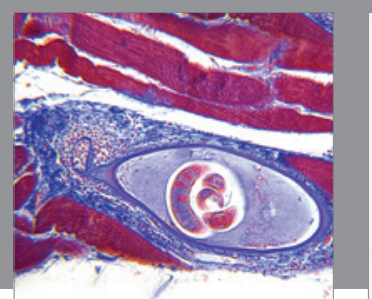

Gastroenterology Research and Practice

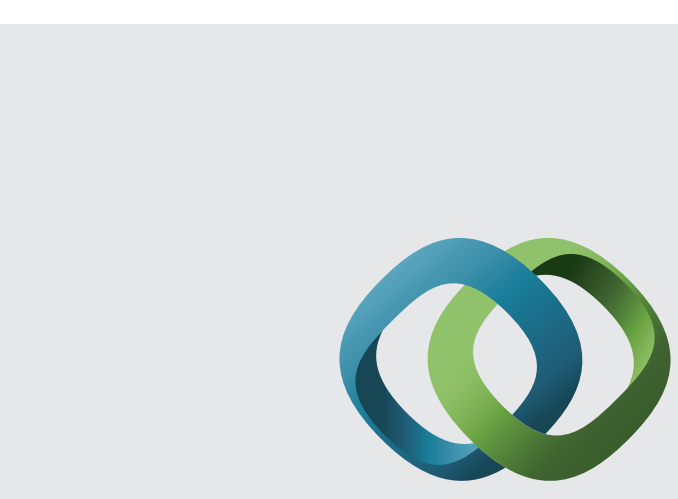

\section{Hindawi}

Submit your manuscripts at

http://www.hindawi.com
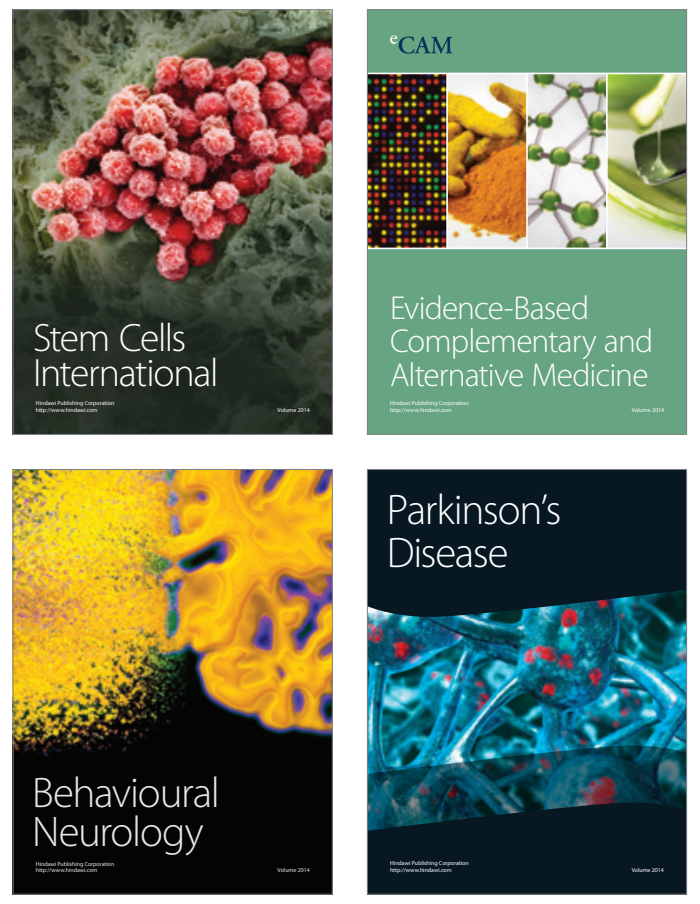
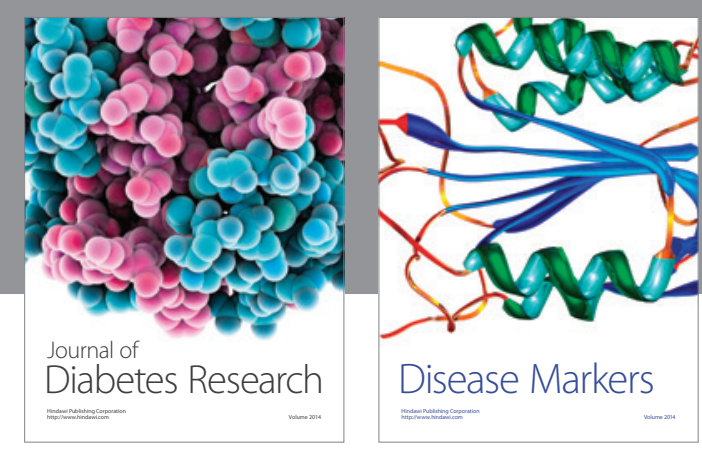

Disease Markers
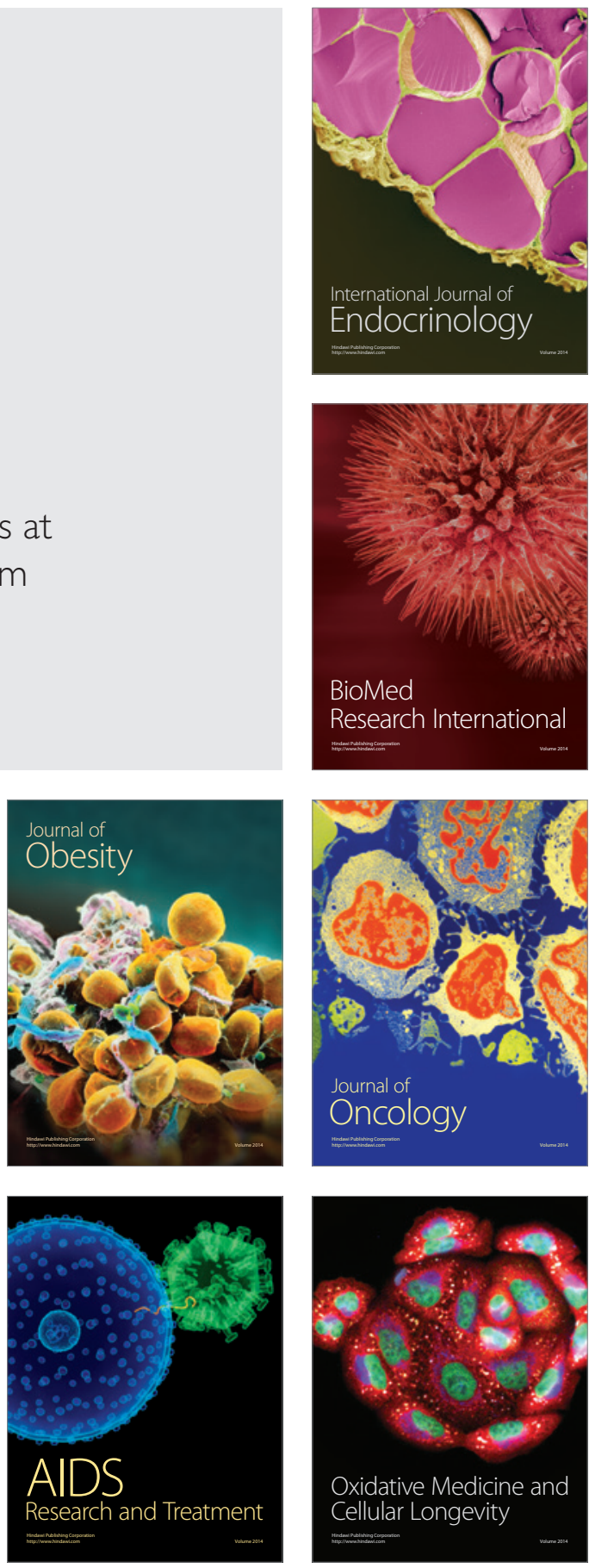